\title{
Reaching the dream of optimal development for every child, everywhere: what do we know about 'how to'?
}

\author{
Anshu Banerjee, ${ }^{1}$ Pia Rebello Britto, ${ }^{2}$ Bernadette Daelmans, ${ }^{1}$ \\ Esther Goh, ${ }^{3}$ Stefan Peterson ${ }^{4}$
}

\section{WHY NOW?}

Early child development (ECD) is fundamental for the health, well-being and life opportunities of every child, everywhere. ${ }^{12}$ It is central to many Sustainable Development Goals (SDGs) and the global child health redesign process, led by WHO and UNICEF. $^{1-3}$ A strong investment case for ECD has been made by academics, as well as large intergovernment investment platforms including G20 and the World Bank. ${ }^{13}$

The Nurturing Care Framework, launched in May 2018, provides a policy roadmap for multiple sectors to enable a world where families and communities can support their children's developmental needs including health, nutrition, safety and security, responsive care and opportunities for early learning. ${ }^{4}$ There is a growing evidence base that inputs especially from preconception to 2 years of age, can improve cognitive, motor, language and socioemotional developmental outcomes, although studies are still small scale and short term. ${ }^{2}$

However, there is a major gap in evidence-based guidance on how to implement at scale, especially in low- and middle-income countries (LMIC). ${ }^{5}$ While policymakers may now be committed to investing for ECD, they face unanswered questions about what, where and how to scale in programmes and especially how to measure progress. Paediatricians and child health workers are well placed to reach the youngest children through routine health systems; yet, they similarly face challenges in considering where to start, what to do, and how to reach the most vulnerable. Parents, caregivers and communities are also key to involve in programme design.

${ }^{1}$ Department of Maternal, Newborn, Child and Adolescent Health, World Health Organization, Geneva, Switzerland

2Early Child Development, UNICEF, Geneva, Switzerland ${ }^{3}$ Bernard van Leer Foundation, The Hague, The Netherlands

${ }^{4}$ Chief of Health, UNICEF, New York City, New York, USA

Correspondence to Dr Stefan Peterson, Chief of Health, UNICEF, New York NY 10017-4414, USA; speterson@unicef.org

\section{WHAT IS NEW?}

This series, involving 33 authors from 24 institutions, including WHO and UNICEF, and coordinated by the London School of Hygiene and Tropical Medicine, outlines evidence to inform these design and implementation decisions. The five papers in the series are organised around an adapted version of a widely used, four-step programme cycle (figure 1) described in detail in the first paper ${ }^{6}$ and involving: (1) situation analyses, (2) planning and implementation, (3) monitoring and evaluation and (4) funding with accountability to drive equity. Three papers build on unique data and learning from 39 ECD projects across 23 LMIC through the Saving Brains ${ }^{\circledR}$ Portfolio of ECD innovations. ${ }^{6-8}$ New evidence from mixed-method evaluation of this portfolio informs how context-specific planning affects reach and, ultimately, impact. ${ }^{6}$

Data regarding programme coverage and quality are fundamental to tracking progress towards scale and yet have received very limited attention to date, with most attention being on outcome measures for ECD. The second paper in this series assesses available data, tools that could be used now, as well as gaps, underlining that indicators can only be defined and tracked if there is a clear intervention and target population. ${ }^{7}$ To track coverage, equity and quality of intervention delivery, much more focus must be placed on advancing routine Health Information Monitoring Systems.

A major challenge is the plethora of tools to assess ECD outcomes at individual and population levels, and the third paper in this series identifies over 100 such tools for use in routine health systems in LMIC, rating them according to explicit accuracy and feasibility criteria. ${ }^{9}$ Yet, no available tools are fit-for-use in routine settings, and most omit vision and hearing. ${ }^{9} \mathrm{WHO}$, UNICEF and the World Bank are partnering to prepare a harmonised approach for measurement of ECD from 0 to 5 years at population level. ${ }^{24}$
The fourth paper provides the first analyses of funding for ECD and assesses US $\$ 79.1$ billion of donor investment from 2007 to 2016 to determine allocations and trends. ${ }^{10}$ Results provide a baseline at the time of the launch of the Nurturing Care Framework in 2018. Encouragingly, there has been an increase in donor funding; though few funds even mention disability, demonstrating the need to integrate care for children with disabilities within approaches that promote ECD. ${ }^{10}$ Domestic investment data to enable tracking of public finance is a major gap generally, ${ }^{10}$ including for ECD. ${ }^{11}$

The fifth and final paper explores stakeholder experiences of scaling ECD initiatives in LMIC contexts, identifying multiple barriers related particularly to the intersectoral nature of ECD. ${ }^{8}$ The role of partnerships in promoting children's development requires coordinated inputs from multiple sectors. Systematic, structured and sustainable ECD initiatives require intentional development driven by better governance, leadership and organisational management.

\section{WHAT NEXT?}

First, while the highest impact on child development outcomes is seen during the first 1000 days, where the health sector has a special role to play, there is a need for strong intersectoral linkages beyond health alone. Multistakeholder and multilevel partnerships take time and investment to establish, sustain and govern, yet are crucial to driving and maintaining change. ${ }^{12}$ Countries such as Chile, Jamaica and Mali have organised national task forces to bring relevant stakeholders within a common platform to address ECD. These efforts need to be linked with the global momentum for Primary Healthcare and Universal Health Coverage, integrated in 'benefit packages'. 13

Second, health professionals play a crucial role-not just at the clinical interface but as champions for the wider scale-up of policies and interventions that support ECD, making the case for policymakers while also leading the change required to develop and implement feasible, sustainable and context-specific solutions. The importance of international collaborations, including South-South networks, in promoting ECD leadership development will be crucial to these efforts at scale.

Third, these papers highlight gaps for future research and action, including the need for research addressing implementation at scale and longer-term outcomes through routine programmes, and for more 


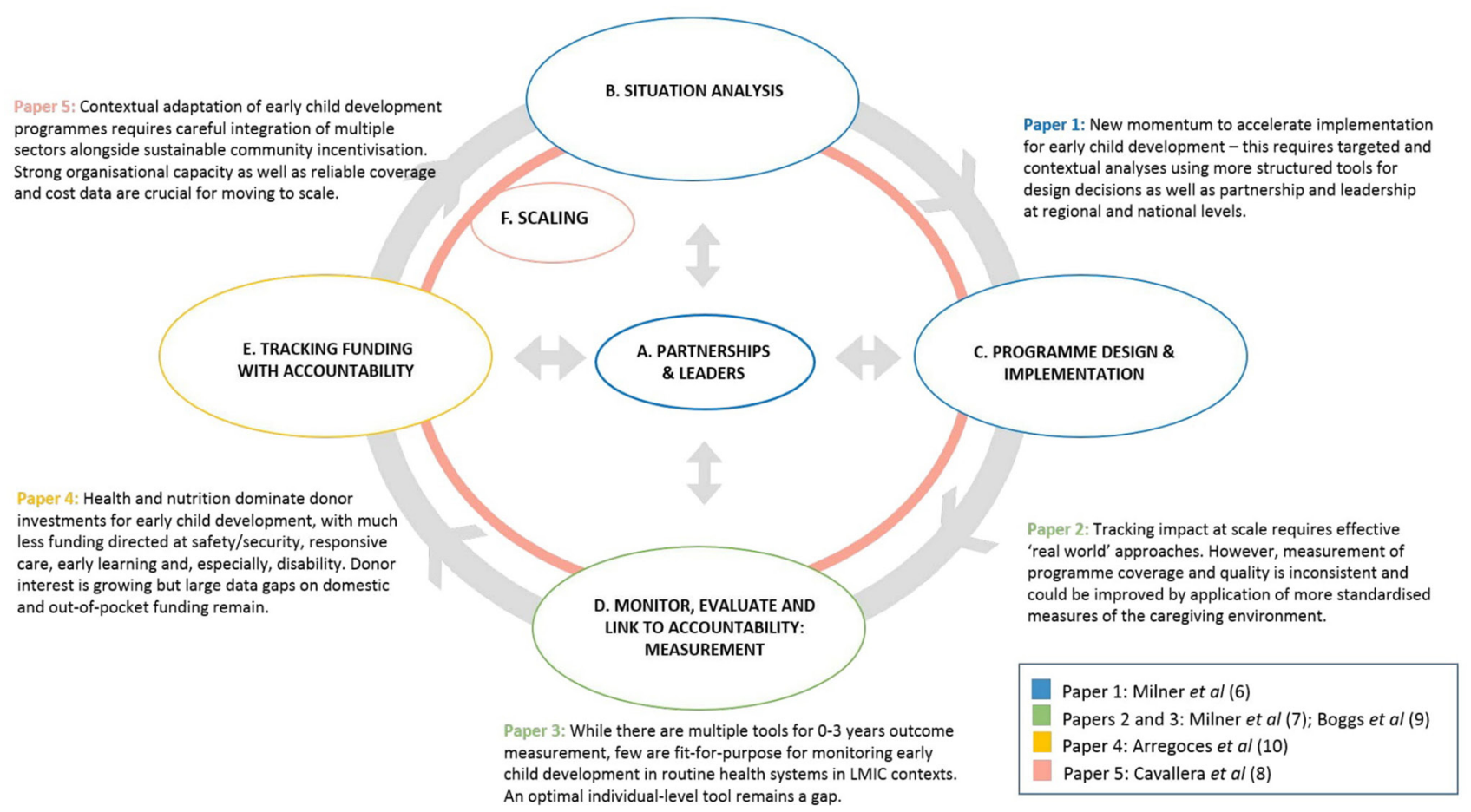

Figure 1 Programme cycle for design, implementation and scaling up of ECD programmes with key findings for each of the five papers in the series 'informing design and implementation for early child development programme'.

consistent measures and more focus on cost-effectiveness. Efforts should also seek to close specific gaps in understanding how to reach the most vulnerable populations, such as children living in extreme poverty, with disabilities or in humanitarian settings.

Finally, this series supports policy-makers in making decisions on how to translate evidence into action. It calls for increased global investment in monitoring and evaluation systems to enable national and global health communities to measure and track change in ECD outcomes and be accountable for fair, needs-based funding allocations. Such accountability is essential to drive progress towards ECD-related SDGs and to ensure that efforts benefit all children, today and tomorrow.

Acknowledgements We are grateful to all authors for their contributions and to the Early Child Development Expert Advisory Group for their guidance, with particular thanks to Joy Lawn, Kate Milner and Victoria Ponce Hardy for inputs on this editorial. We thank Nick Brown and Trevor Duke from Archives for suggestions. We thank all the project innovators, participants and families involved in the Saving Brains portfolio.

Funding This series was made possible by funding from the Bernard van Leer Foundation. Saving Brains impact and process evaluation was funded by Grand Challenges Canada ${ }^{\circledR}$. No specific funding was received for this editorial.

Disclaimer The authors alone are responsible for the views expressed in this article and they do not necessarily represent the views, decisions or policies of the institution with which they are affiliated.
Competing interests None declared.

Patient consent for publication Not required.

Provenance and peer review Commissioned; internally peer reviewed.

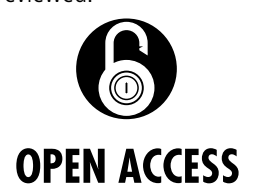

Open access This is an open access article distributed in accordance with the Creative Commons Attribution Non Commercial (CC BY-NC 4.0) license, which permits others to distribute, remix, adapt, build upon this work non-commercially, and license their derivative works on different terms, provided the original work is properly cited, appropriate credit is given, any changes made indicated, and the use is non-commercial. See: http:// creativecommons.org/licenses/by-nc/4.0/.

(c) Author(s) (or their employer(s)) 2019. Re-use permitted under CC BY-NC. No commercial re-use. See rights and permissions. Published by BMJ.

\section{D) Check for updates}

To cite Banerjee A, Britto PR, Daelmans B, et al. Arch Dis Child 2019;104:S1-S2.

Received 20 February 2019

Accepted 21 February 2019

Arch Dis Child 2019;104:S1-S2

doi:10.1136/archdischild-2019-317087

\section{REFERENCES}

1 Black MM, Walker SP, Fernald LCH, et al. Early childhood development coming of age: science through the life course. Lancet 2016:389:77-90.
2 Britto PR, Lye SJ, Proulx K, et al. Nurturing care: promoting early childhood development. Lancet 2016;389:91-102.

3 United Nations. Sustainable development goals: United Nations, 2015.

4 World Health Organisation. Nurturing Care Framework. Geneva: World Health Organisation, 2018. https://www.who.int/maternal_child_ adolescent/documents/nurturing-care-early-childhooddevelopment/en/

5 Britto PR, Singh M, Dua T, et al. What implementation evidence matters: scaling-up nurturing interventions that promote early childhood development. Ann NY Acad Sci 2018;1419:5-16.

6 Milner KM, Bernal R, Brentani A, et al. Contextual design choices and partnerships for scaling early child development programmes. Arch Dis Child 2018;104(Suppl 1):S3-S12

7 Milner KM, Bhopal S, Dua T, et al. Counting outcomes, coverage and quality for early child development programmes. Arch Dis Child 2019;104(Suppl 1): S13-S21.

8 Cavallera V, Tomlinson M, Radner J, et al. Scaling early child development: what are the barriers and enablers? Arch Dis Child 2019;104(Suppl 1): S43-S50.

9 Boggs D, Milner KM, Black M, et al. Rating early child development outcome measurement tools for routine health programme use. Arch Dis Child 2019; 104(Suppl 1):S22-S33.

10 Arregoces L, Hughes R, Tann C, et al. Accountability for funds for Nurturing care: what can we measure? Arch Dis Child 2019;104(Suppl 1):S34-S42.

11 Richter LM, Desmond C, Behrman J, et al. G20's initiative for early childhood development. Lancet 2018;392:2695-6.

12 Richter LM, Daelmans B, Lombardi J, et al. Investing in the foundation of sustainable development: pathways to scale up for early childhood development. Lancet 2016:389:103-18.

13 WHO, UNICEF. Declaration of Astana. Global Conference on Primary Health Care, 2018. 